\title{
"O Rio Grande do Sul é a Hungria do Brasil, é a província em que todos sabem andar a cavalo": turfe, hipódromos e modernidade em Porto Alegre nas últimas décadas do século XIX
}

\author{
"Rio Grande do Sul is Brazil's Hungary, it is the province \\ where everyone knows how to ride a horse": turf, \\ hippodromes and modernity in Porto Alegre from the last \\ decades of the 19 th century
}

Cleber Eduardo Karls*

\begin{abstract}
Resumo
Este estudo busca problematizar aspectos relativos à prática do turfe na cidade de Porto Alegre nas últimas três décadas do século XIX. Procuramos relacionar esta atividade às ideias de modernidade em pauta assim como com as características culturais locais que moldaram o esporte a este contexto e às suas peculiaridades regionais. Abordamos de forma mais enfática em nossa investigação os locais de prática dessa atividade, ou seja, os hipódromos. Além disso, pautamos a discussão acerca do desenvolvimento racial dos cavalos de corrida frente aos "crioulos" sul-rio-grandenses, à luz das ideias de modernidade efervescentes à época. Para esta abordagem, utilizamos como fonte os periódicos publicados na cidade de Porto Alegre no período em tela, especialmente A Federação, A Reforma, Correio do Povo, Gazeta da Tarde e Gazeta de Porto Alegre. Dessa forma, o desenvolvimento do turfe nas últimas três décadas do século XIX em Porto Alegre pôde ser percebido como o resultado de uma miscigenação entre distintas variáveis culturais, étnicas e geográficas regionais com ideias importadas, especialmente relacionadas a modernidade e a prática esportiva, que deram origem a um esporte carregado de particularidades inerente a esses componentes.
\end{abstract}

Palavras-Chave: Turfe, Esporte, Modernidade, Porto Alegre, Século XIX

\section{Abstract}

This study seeks to highlight aspects related to the practice of horseback racing in the city of Porto Alegre in the last three decades of the 19th century. We try to relate this activity to the ideas of modernity in question as well as to the local cultural characteristics that shaped the sport in this context and its regional

*Doutor em História Comparada pela Universidade Federal do Rio de Janeiro (UFRJ), Professor dos cursos de História (presencial e EaD) da Universidade Veiga de Almeida. E-mail: cleber_hist@yahoo.com.br 
peculiarities. In our investigation, we will approach more emphatically the places of practice of this activity, that is, the racetracks. In addition, we will discuss the racial development of racehorses as compared to the "Creoles" of Rio Grande do Sul in the light of the ideas of modernity effervescent at the time. For this investigation, we will use as source the periodicals published in the city of Porto Alegre in the period at stake, especially A Federação, A Reforma, Correio do Povo, Gazeta da Tarde and Gazeta de Porto Alegre. The development of turf in the last three decades of the nineteenth century in Porto Alegre could be perceived as the result of a miscegenation between different regional cultural, ethnic and geographical variables with imported ideas, especially related to modernity and sports, which gave rise to a peat-laden sport inherent in these components.

Keywords: Turf, Sport, Modernity, Porto Alegre, 19th century

As corridas de cavalo foram práticas regulares no século XIX no Rio Grande do Sul. Esta era uma atividade que estava ligada a muitas características sociais e culturais locais, que faziam do equino um personagem do cotidiano sul-rio-grandense. Essas disputas, carreiras de cancha reta ${ }^{1}$ e demais provas de habilidade, estavam inseridas no contexto social daquele período em que a relação do homem sulino junto aos animais era naturalizada frente a um complexo conjunto de variáveis. Com o desenrolar do período oitocentista, as rústicas carreiras cederam, parcialmente, lugar a uma nova prática oriunda de terras britânicas, representante de ideias progressistas e de modernidade, o turfe. 0 esporte inglês reorganizou "antigas" disputas, inserindo ares civilizados a uma prática que já fazia parte da rotina porto-alegrense. Disciplinou, acrescentou novas regras e modos "importados" a

\footnotetext{
${ }^{1}$ As "carreiras de cancha reta" eram corridas de cavalo realizadas em linha reta, muito populares no Rio Grande do Sul nos séculos XIX e XX. Mesmo com o surgimento e a ampliação da prática do turfe no Rio Grande do Sul a partir do período oitocentista, esta atividade continuou existindo concomitantemente, principalmente nas áreas rurais onde era um divertimento usual. Para saber mais, ver: GOLIN, Tau. O povo do pampa: uma história de 12 mil anos do Rio Grande do Sul para adolescentes e outras idades. 3. ed. Passo Fundo: Ed. da UPF, 2004.
} 
remotos costumes, a exemplo do que vinha acontecendo em importantes cidades do Brasil, como a sua capital a época, o Rio de Janeiro ${ }^{2} .3,4$

Neste período, Porto Alegre apresentava uma tímida participação na vida política e econômica brasileira e sua função se limitava ao fornecimento de gêneros primários e a guarda da fronteira nacional. O Rio Grande do Sul teve, também no século XIX, como característica marcante, o recebimento de correntes imigratórias europeias que contribuíram na geração e tiveram destaque no desenvolvimento de vários esportes, assim como clubes e associações esportivas.

Nessa amálgama conjuntural no sul do Brasil oitocentista, é possível destacar o papel dos adventícios teutos, tanto no que se refere ao desenvolvimento esportivo quanto da modernização da urbe, como sublinha Pesavento:

o binômio modernização-modernidade é eminentemente urbano, tendo na cidade o seu espaço preferencial de realização. É nesse contexto que se inserem os alemães e seus descendentes, como agentes de um processo de transformação econômico-social capitalista, expresso no desenvolvimento do grande comércio, da indústria, dos bancos da renovação urbana. Executores de um processo de modernização, os alemães propiciaram as condições para que a experiência histórica da modernidade se generalizasse e se difundisse entre os consumidores dos efeitos da modernização. ${ }^{5}$

Aliado a outras variáveis apontadas, a posição fronteiriça de Porto Alegre em relação aos países platinos é outro aspecto marcante para a compreensão da sua formação e relevância na composição do campo esportivo nacional. Esse hibridismo cultural e, também, a proximidade entre as práticas rurais e urbanas, especialmente no trato com os animais, é fator importante para compreendermos as especificidades da composição esportiva porto-alegrense. ${ }^{6}$

\footnotetext{
${ }^{2}$ Sobre o surgimento e desenvolvimento do turfe e de demais esportes no Rio de Janeiro e em outras importantes cidades brasileiras no século XIX, ver: MELO, Victor Andrade de. (Org.). Os sports e as cidades brasileiras: transição dos séculos XIX e XX. Rio de Janeiro: Apicuri, 2010.

${ }^{3}$ KARLS, Cleber Eduardo. Modernidades sortidas: o esporte oitocentista em Porto Alegre e no Rio de Janeiro. Rio de Janeiro, RJ. Tese de Doutorado. Programa de Pós-Graduação em História Comparada, Universidade Federal do Rio de Janeiro, 2017.

${ }^{4}$ Destacamos que temos ciência da larga produção historiográfica que possui aderência ao tema que aqui estamos discutindo. No entanto, visto os limites regulamentares de extensão e as características de um artigo científico, optamos por utilizar aquelas referências que julgamos contribuir de forma mais direta para os objetivos desse trabalho.

${ }^{5}$ PESAVENTO, Sandra Jatahy. De como os alemães tornaram-se gaúchos pelos caminhos da modernização. In. MAUCH, Claudia (Org.). Os alemães no sul do Brasil. Canoas: Ed. ULBRA, 1994, p. 200.

${ }^{6}$ KARLS, Op. Cit.
} 
Da mesma forma, aponta Sandra Pesavento, que era um grande desafio para a elite cultural e política da capital sul rio-grandense construir a "modernidade urbana numa província tradicionalmente rural e com forte identidade regional apoiada no campo; uma província que não era o centro decisório do poder nacional mas que dele se encontrava próxima". ${ }^{7}$ Adotar hábitos "civilizados", neste caso o turfe, que acarretaria mudanças de costumes considerados obsoletos e, de certa forma, "selvagens", estaria de acordo com este objetivo e merecia ser incentivado.

Modernizar significava aproximar a capital do Rio Grande do Sul a um modelo inspirado em ideias "importadas", que valorizavam aspectos ligados a valores considerados "superiores", que a assemelhassem às principais referências mundiais que eram as metrópoles europeias. Ratificando essas considerações, Marshall Berman afirma que a modernidade e, consequentemente, o pensamento moderno, seguem se desenvolvendo e não enquadrado em um formato pré-definido. Essas características estão especialmente identificadas com a nova dinâmica industrial e urbana. No nosso caso, característica do final do século XIX, na capital mais meridional do Brasil. Todavia, não existe uma única definição que englobe o conjunto de tudo o que podemos relacionar a modernidade, já que o pensamento moderno é, também, subjetivo e resultado do contexto onde é produzido. Com efeito, aponta o pensador algumas especificidades em relação a esse ambiente:

O turbilhão da vida moderna tem sido alimentado por muitas fontes: grandes descobertas nas ciências físicas, com a mudança da nossa imagem do universo e do lugar que ocupamos nele; a industrialização da produção, que transforma conhecimento em tecnologia, cria novos ambientes humanos e destrói os antigos, acelera o próprio ritmo de vida. ${ }^{8}$

Desta forma, os esportes e sua organização, suas regras e seus objetivos, faziam parte de uma série de variáveis neste contexto e eram sinônimos de progresso e evolução. Essas práticas modernas e modernizantes encontraram ambientes fecundos, mas diversos para a sua prosperidade, diferente daquelas do antigo mundo. Inseridas em realidades diferenciadas, as atividades esportivas se espraiaram, se adaptaram e se moldaram às condições de cada local. As ideias de modernidade e neste contexto, também, a indústria do

\footnotetext{
${ }_{7}^{7}$ PESAVENTO, Sandra Jantahy. O imaginário da cidade: visões literárias do urbano - Paris, Rio de Janeiro, Porto Alegre. 2 ed. Ed. Universidade UFRGS: Porto Alegre, 2002, p. 271.

${ }^{8}$ BERMAN, Marshall. Tudo que é sólido desmancha no ar: a aventura da modernidade. São Paulo: Companhia das Letras, 1986. p. 16.
} 
entretenimento, se desenvolveram inseridas em uma conjuntura inerente à época que atingiu tanto o Brasil quanto grande parte do mundo ocidental.

Não parecia haver, nesse cenário, qualquer incoerência entre o lucro e o lazer. Os esportes e, consequentemente, as demais atividades de entretenimento "poderiam servir para reforçar laços e estratégias comerciais quanto se tornar possibilidades de investimento, tão logo as camadas populares começassem também a ocupar o seu tempo livre, buscando alternativas em um mercado gerenciado pelos novos empresários" ". Porto Alegre, a seu modo e com suas peculiaridades, foi fortemente influenciada por essa tendência, onde o turfe estava inserido.

Com efeito, é nesse intuito que uma nova postura em relação aos certames alterou o perfil das corridas de cavalo que há muito eram praticadas na cidade, anteriormente a implementação do esporte britânico. Nas palavras de Achylles Porto Alegre ${ }^{10}$, antes mesmo dos hipódromos, as provas eram realizadas num trecho de estrada ou na Várzea, nas imediações do Colégio Militar, atual Parque da Redenção, região central da cidade. Era a cancha preferida. Ainda completa:

Ali se reuniam, aos domingos e dias feriados, os moradores dos subúrbios e dos
povoados vizinhos, que tinham paixão pelas corridas de cavalos. Desde bem
cedo começavam então a convergir para esse sítio os que tinham interesse pelo
divertimento tão apreciado pelos nossos antepassados. Muitos patrícios eram
infalíveis ali, vindo mesmo com mau tempo e de longe. ${ }^{11}$

A capital do Rio Grande do Sul seguia, à sua maneira, os passos da mais importante cidade do país, o Rio de Janeiro. Na capital brasileira, de acordo com $\mathrm{Melo}^{12}$, por trás do desenvolvimento pioneiro e do interesse privilegiado pelo turfe em relação a outros esportes, alguns fatores devem ser levados em consideração. Os cavalos, assim como no Rio Grande do Sul, mas num patamar um pouco diferenciado, há muito ocupavam importante função na sociedade como meio de transporte e carregamento. Além disso, a utilização dos equinos já estava ligada a atividades de diversão, como cavalhadas e touradas, assim como acontecia em Porto Alegre ${ }^{13}$.

\footnotetext{
${ }^{9}$ MELO, Victor Andrade de (Org.). Os sports e as cidades brasileiras: transição dos séculos XIX e XX. Rio de Janeiro: Apicuri, 2010. p. 9.

${ }^{10}$ PORTO ALEGRE. Achylles. História popular de Porto Alegre. Porto Alegre, UE/Porto Alegre, 1994.

${ }^{11}$ Ibidem, p. 102.

${ }^{12}$ MELO, Victor Andrade de. Cidade sportiva: primórdios do esporte no Rio de Janeiro. Rio de Janeiro: Relume Dumará, FAPERJ, 2001.

${ }^{13}$ Sobre as touradas em Porto Alegre no século XIX, ver: KARLS, Cleber Eduardo; MELO, Victor Andrade
} 
A inspiração para a instalação do turfe no Brasil e, consequentemente, em Porto Alegre, era o esporte inglês e francês. Do velho mundo vinha o modelo de competição, com suas regras e nomenclaturas, até mesmo a ideia de superioridade que uma prática europeia causava à época. Os hipódromos inauguravam um novo local de sociabilidade, com novos hábitos inspirados no antigo continente. No caso da capital fluminense, ambientes onde os membros da elite nacional, de origem principalmente rural, podiam exercitar o seu sentimento de distinção, com suas belas vestimentas, a exemplo do que já acontecia na Inglaterra e na França. ${ }^{14}$

No caso brasileiro, o Rio de Janeiro pode ser considerado o embrião deste esporte. Com a publicação de um manifesto, o ano de 1847 registrou a primeira tentativa de organização de um clube de turfe brasileiro criado especialmente para a prática esportiva. O Club de Corridas, como foi chamado, realizou sua atividade inicial em 1849. Toda sua estrutura, normas e regulamentos seguiram o modelo europeu, e foi referência para grande parte do desenvolvimento turfístico do Brasil ${ }^{15}$.

Entre os anos de 1870 e 1890, o turfe tornou-se uma das diversões preferidas, assim como assunto obrigatório em jornais, tendo influenciado vários costumes, como o linguajar e o vestuário. No final de 1880 e nos primeiros anos da década seguinte, o Rio de Janeiro possuía cinco hipódromos: o Jockey Club (mais antigo), o Turf Club, o Clube do Prado Guarani, o Hipódromo Nacional e o Derby Club. Este último surgiu em 1885, organizado por um grupo de sócios oriundos do extinto Derby Fluminense, que, por sua vez, era originário do Club de Corridas Vila Isabel. ${ }^{16}$

Mesmo em um contexto diferenciado de status em relação ao Rio de Janeiro, Porto Alegre também adotou o turfe como um dos seus mais consagrados esportes. O Prado Jacome, localizado no Campo do Bom Fim (também chamado de Campo da Redenção), foi o primeiro a se estabelecer, sendo que, até o final do século XIX, quatro outros hipódromos já existiam, o que evidencia o rápido desenvolvimento do esporte e sua popularização, que tomou conta de alguns bairros importantes da cidade, como: Prado Rio-Grandense (Menino Deus), Prado Boa-Vista (Partenon), Prado Independência (Moinhos

de. Tradição e modernidade: as touradas na Porto Alegre do século XIX. História Unisinos, São Leopoldo, Vol. $18 \mathrm{n}^{\mathrm{o}} 2$, maio/agosto 2014.

${ }^{14}$ MELO, Victor Andrade de. Cidade sportiva: primórdios do esporte no Rio de Janeiro. Op. Cit.

${ }^{15}$ Ibidem, p. 31-32.

${ }^{16}$ MELO, Victor Andrade de. Corpos, bicicletas e automóveis: outros esportes na transição do século XIX e XX. In.: DEL PRIORE, Mary; MELO, Victor Andrade de(Orgs.). História do esporte no Brasil: do império aos dias atuais. São Paulo: Editora UNESP, 2009, p. 49. 
de Vento) e Prado Navegantes (Navegantes), conforme podemos verificar no mapa a seguir.

Imagem 1: Planta da cidade de Porto Alegre (1896) ${ }^{17}$

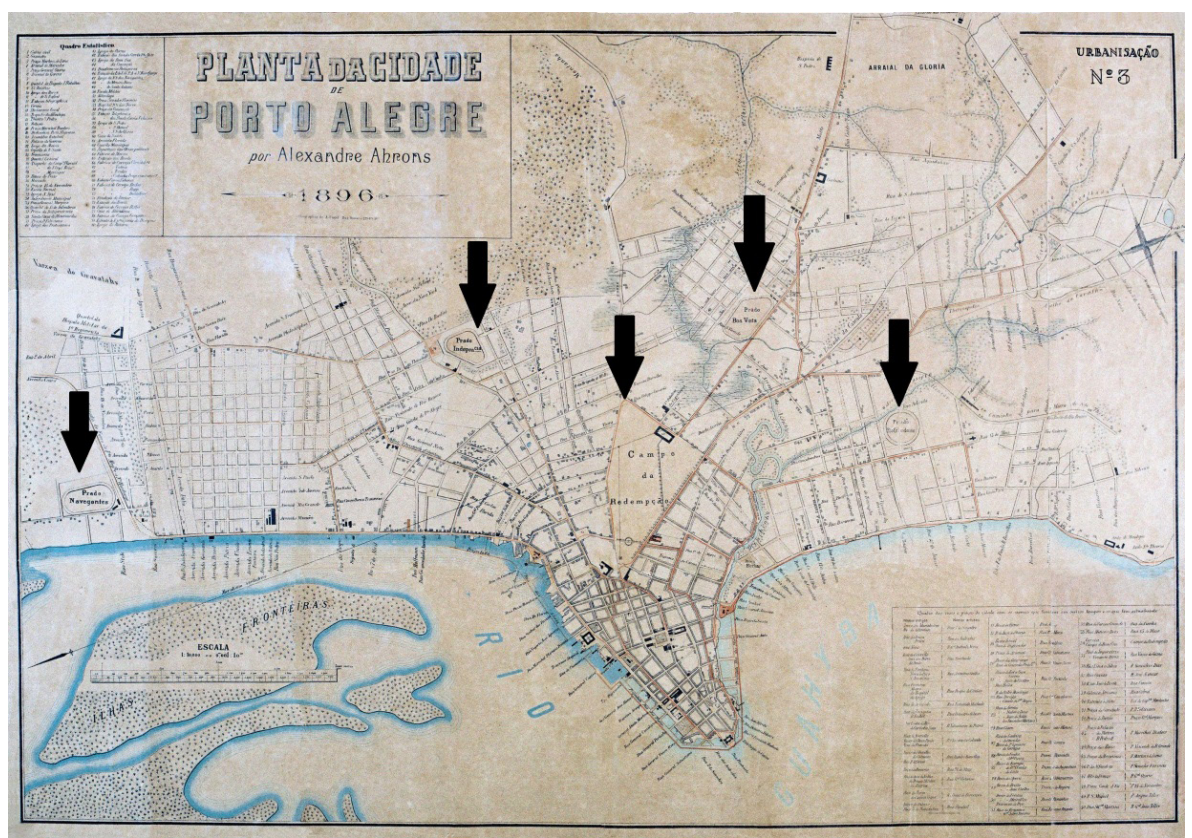

Fonte: Instituto Histórico e Geográfico do Rio Grande do Sul. Cartografia virtual histórico-urbana de Porto Alegre - século XIX e início do XX. Porto Alegre, 2005. 1 CD-ROOM. (Grifos nossos)

Em um contexto de reconfiguração física e social e crescimento da capital do Rio Grande do Sul nas últimas décadas do período oitocentista, os esportes e os seus locais de prática ganharam destaque nessa função, como bem apontam Goellner e Mazo:

Os prados, também chamados hipódromos, constituíam-se como locais de socialização e relacionavam-se com a vida chic da cidade. Homens e mulheres compareciam para ver e serem vistos. Desfilavam com elegância, faziam apostas,

\footnotetext{
${ }^{17}$ Estão identificados com as setas negras, os quatro hipódromos existentes na cidade, ao final do Século XIX, assim como o Campo da Redenção, que foi local privilegiado para a instalação de circos, práticas esportivas e divertimentos.
} 
excitavam-se com os páreos, negociavam, divertiam-se, rompiam com a rotina, preocupavam-se com os ditames da moda. ${ }^{18}$

Com efeito, é importante ressaltar que a ampliação dos ambientes públicos de socialização, em um contexto concomitante e dependente ao desenvolvimento do campo esportivo e da indústria do entretenimento facilitaram e proporcionaram a participação cada vez mais frequente de mulheres nos hipódromos, causando uma nova configuração social num cenário, até então, amplamente dominado por homens. ${ }^{19} \mathrm{~A}$ incipiente participação feminina não ficaria restrita a essa prática esportiva. Outros esportes e divertimentos em Porto Alegre nas últimas décadas do século XIX, como patinação (rinks), ciclismo, circo, entre outros, dariam destaque às mulheres, tanto como protagonistas ou público. ${ }^{20}$

Desta forma, buscamos neste artigo problematizar aspectos relativos ao desenvolvimento e a prática do turfe na cidade de Porto Alegre no século XIX, especialmente no que se refere às suas especificidades locais em relação a sua execução e relação com as ideias de modernidade. Ou seja, o mesmo turfe que era praticado no antigo mundo ou no centro do Brasil, mas com especificidades regionais em Porto Alegre.

Procuramos relacionar esta atividade às características culturais locais que moldaram o esporte a este contexto e às suas peculiaridades conjunturais. Abordamos de forma mais enfática em nossa investigação os locais de prática dessa atividade, ou seja, os hipódromos. Além disso, pautamos a discussão acerca do desenvolvimento racial dos cavalos de corrida frente aos "crioulos" sul-rio-grandenses, à luz das ideias de modernidade efervescentes à época. Para esta abordagem, utilizamos como fonte os periódicos publicados na cidade de Porto Alegre no período em tela, especialmente A Federação, A Reforma, Correio do Povo, Gazeta da Tarde e Gazeta de Porto Alegre.

Levando em consideração que a imprensa local já demonstrava vigor na época observada, ${ }^{21}$ torna-se fundamental a análise destes documentos. Os

\footnotetext{
${ }^{18}$ GOELLNER, Silvana Vilodre; MAZZO, Janice Zarpelon. Esporte, cidade e modernidade: Porto Alegre. In. MELO, Victor Andrade de (Org.). Os sports e as cidades brasileiras: transição dos séculos XIX e XX. Rio de Janeiro: Apicuri, 2010. p. 179.

${ }^{19}$ GOELLNER, Silvana Vilodre. Mulher e esporte no Brasil: entre incentivos e interdições elas fazem história. Pensar a Prática, v. 8, n. 1, p. 85-100, 15 nov. 2006.

${ }^{20}$ KARLS, Op. Cit.

${ }^{21}$ HOHLFELDT, Antonio; RAUSCH, Fábio Flores. A imprensa sul-rio-grandense entre 1870 e 1937: discussão sobre critérios para uma periodização. In: Congresso Brasileiro de Ciências da Comunicação, XXIX, Brasília, 2006. Disponível em: http://www.intercom.org.br/papers/nacionais/2006/resumos/R0431-1.pdf. Acesso em: 01/05/2017.
} 
jornais são fontes privilegiadas, que contém informações e sensibilidades sobre o cotidiano. Nesse sentido, concordamos com Luca, ${ }^{22}$ quando ressalta que a imprensa se valorizou enquanto fonte quando a própria história percebeu a sua incapacidade de dar respostas globais e construir verdades. A pesquisa histórica passou a apreciar e considerar novos documentos que não eram mais os detentores das respostas a todas as perguntas, mas, sim, representantes de valiosas interpretações e representações de um tempo. Nesse conjunto, a imprensa se encaixa exatamente, com suas opiniões, posições, impressões, destaques e tudo o que faz dela uma riquíssima fonte de informações.

Nesse sentido, percebemos os periódicos enquanto registros carregados de marcas de um tempo, de objetividades e subjetividades apresentadas através de representações. Por esse motivo, apontamos que essa é uma investigação identificada com a história cultural, especialmente, no seu maior campo de atuação que são as representações. De acordo com Roger Chartier, as representações podem ser entendidas como "o instrumento de um conhecimento mediato que revela um objeto ausente, substituindo-o por uma 'imagem' capaz de trazê-lo à memória e 'pintá-lo' como é”23 . Da mesma forma, a historiador brasileira Sandra Pesavento destaca especial importância às representações na história cultural:

A representação é uma construção imagética e discursiva que enuncia ou
presentifica o outro - no caso, recria o real. Neste processo, a evocação não
precisa ter correspondência reflexa com o objeto representado. Ou seja, a
adequação das representações não se mede por critérios de autenticidade ou
veracidade, mas pela sua capacidade mobilizadora, de motivar práticas sociais
e de granjear credibilidade, indo ao encontro daquilo que os indivíduos visam,
sonham, esperam, temem...

No entanto, temos clareza sobre os limites dos periódicos que priorizamos utilizar como fonte de pesquisa. Ao mesmo tempo, sabemos que nenhum trabalho histórico tem condições de dar conta de toda uma complexidade intempestiva. Portanto, mesmo circunscrita como qualquer outra fonte que pudesse ser utilizada, a imprensa representa uma leitura de uma época em determinado local que tem suas peculiaridades e que, ricamente, contribui para a interpretação de um processo a partir de um tipo de olhar e um cunho

\footnotetext{
${ }^{22}$ LUCA, Tania Regina de. Fontes impressas: história dos, nos e por meio dos periódicos. In. PINSKY, Carla Bassanezi. Fontes históricas. 3 ed. São Paulo: Contexto, 2011.

${ }^{23}$ CHARTIER, Roger. À beira da falésia. Porto Alegre, Ed. da UFRGS, 2002. p. 74.

${ }^{24}$ PESAVENTO, Sandra Jatahy. Imagens da Violência: o discurso criminalista na Porto Alegre do fim do século. In: Humanas: revista do IFCH - UFRGS, Porto Alegre, v. 16, n.2, jul./dez., 1993. p. 112.
} 
de discurso. Concomitantemente, cabe ao pesquisador lançar a sua visão crítica sobre ele e, através da sua habilidade e compreensão contextual, tentar encaixar as peças e montar o quebra-cabeça histórico.

Com efeito, cabe aqui um pequeno detalhamento das características destes informativos.

A Federação foi um importante veículo de comunicação do Partido Republicano Rio-grandense. Fundado em 1884, permaneceu ativo até 1937 quando foi extinto por ato censorial. ${ }^{25}$

Vinculado ao Partido Liberal de Gaspar Martins, foi fundado em 1869 A Reforma. Sua circulação permaneceu efetiva, mesmo sofrendo repressão do governo de Julio de Castilhos após a Revolução Federalista (1893-1895). Fechou suas portas no ano de $1912 .{ }^{26}$

O Correio do Povo pode ser considerado o primeiro jornal civil do Rio Grande do Sul, que nasceu em 1895, principalmente, com o cansaço e o desgaste que os partidos políticos sofreram com a Revolução de 1893. Este inaugurou um novo perfil de imprensa, dando ênfase a anúncios pagos e ampliando os espaços destinados a entretenimento nas suas páginas. ${ }^{27}$

A Gazeta da Tarde iniciou suas atividades no ano de 1895 e era um folhetim que tinha posicionamentos muito relacionados a um de seus principais nomes: Germano Hasslocher, ${ }^{28}$ importante figura do campo político e esportivo de Porto Alegre. Ele tinha uma forte ligação com os teuto-brasileiros. Era um periódico conhecido e respeitado por uma camada restrita da população. ${ }^{29}$

Por fim, a Gazeta de Porto Alegre foi um jornal diário fundado em 1879 que teve como diretor Carlos Von Koseritz. Em suas colunas escreveram vários intelectuais como Álvaro Pereira Coruja e Ramiro Barcelos. Encerrou suas atividades em $1884 .^{30}$

\footnotetext{
${ }^{25}$ HOHLFELDT, Antonio; RAUSCH, Fábio Flores. A imprensa sul-rio-grandense entre 1870 e 1937: discussão sobre critérios para uma periodização. Op. Cit.

${ }^{26}$ HOHLFELDT, Antonio. A imprensa sul-rio-grandense entre 1870 e 1930. E-compós: Revista da Associação Nacional dos Programas de Pós-Graduação em Comunicação, 7. 2006. Disponível em: http://www.compos.org. br/seer/index.php/e-compos/article/viewFile/118/117. Acesso em: 01/05/2017.

${ }^{27}$ Ibidem.

${ }^{28}$ Para saber mais sobre a atuação de Germano Hasslocher no campo esportivo de Porto Alegre no século XIX, ver: KARLS, Cleber Eduardo. Modernidades sortidas: o esporte oitocentista em Porto Alegre e no Rio de Janeiro. Op. Cit.

${ }^{29}$ FERREIRA, Athos Damasceno. Imprensa literária de Porto Alegre no século XIX. Porto Alegre: Editora da Ufrgs, 1975.

${ }^{30}$ FRANCO, Sergio da Costa. Porto Alegre: guia histórico. 4 ed. Porto Alegre: Editora da UFRGS, 2006.
} 


\section{Os Hipódromos: a materialização de um projeto de modernidade}

Tivemos acesso à primeira notícia de corrida em um hipódromo na capital sul-rio-grandense, referente a uma disputa do dia 11 de agosto do ano de 1872. Esse anúncio foi publicado no jornal A Reforma, em 30 de julho do mesmo ano. ${ }^{31}$ A missiva prevenia os sócios do Club de Corridas, assim como o público em geral, sobre a disputa que se realizaria no Prado Jacome, privativo de amadores. $O$ anúncio que destacava essa atividade como passatempo, fez algumas orientações aos competidores que deveriam declarar o nome dos corredores e cavalos, assim como as características principais dos animais, como pelagem, idade, sinais mais salientes, e, também, as cores das vestimentas dos jockeys. Não obtivemos uma fonte precisa sobre a data exata da primeira competição, mas temos 1872 como o ano que se destacou como o ponto inicial da prática do turfe em Porto Alegre, corroborado nas pesquisas de Del Priore e Melo..$^{32}$ Porto Alegre estava, portanto, conectada ao processo de desenvolvimento esportivo e, no caso, do turfe, que já acontecera na capital do Império em 1847 com a publicação de um manifesto que daria origem ao Club de Corridas, cuja primeira atividade aconteceria em $1849 .{ }^{33}$

$\mathrm{Na}$ edição do dia 25 de agosto de 1872, o jornal A Reforma publicou os resultados de uma corrida realizada no Prado Jacome no dia 18 do mesmo mês. Notamos que as informações indicam que essa não foi a disputa inicial, mas uma das primeiras realizadas naquele local. o periódico depôs que "as corridas do último domingo, posto que não apresentasse a animação das primeiras com que foi inaugurado o Prado, estiveram concorridas, apesar de o dia ameaçar chuva". ${ }^{34}$

Confirmamos que o Jacome foi o pioneiro do turfe em Porto Alegre, quando analisamos um artigo publicado na Gazeta de Porto Alegre, em 15 de maio de 1880 que ratificou este dado. O texto tem como título "inauguração do hipódromo" e trata da abertura do Hipódromo Porto-Alegrense, que se realizaria no dia 23 de maio de 1880 . Nessa menção, o jornal fez referência às primeiras corridas de turfe, que ocorreram na cidade, onde o Jacome e o seu fundador foram citados como os precursores do esporte em Porto Alegre: "tivemos aqui uma tentativa; foi a feita no tempo em que aqui se achava o Hypologo brasileiro Sr. Luiz Jacome, que fundou um Jockey-Club, mas com sua retirada

\footnotetext{
${ }^{31}$ A Reforma, Porto Alegre, 30/07/1872, p. 2.

${ }^{32}$ DEL PRIORE, Mary; MELO, Victor Andrade de (Orgs.). História do esporte no Brasil: do império aos dias atuais. São Paulo: Editora UNESP, 2009. p. 50.

${ }^{33}$ Ibidem, p. 47-48.

${ }^{34}$ A Reforma, Porto Alegre, 25/08/1872, p. 2.
} 
da província adormeceu o útil instituto". Seria, portanto, o Porto-Alegrense, a segunda tentativa que, definitivamente, "não só atrairá grande concorrência a festa inicial, senão que se conservará também vivo o interesse por esta tão útil instituição". 35

Da mesma forma, a Gazeta de Porto Alegre exaltava os benefícios desse novo empreendimento que incorporaria a capital do Rio Grande do Sul aos costumes de outros grandes centros, sublinhando que "era realmente tempo que Porto Alegre imitasse o exemplo da corte, de S. Paulo, de Pelotas, que todos possuem clubs de corridas em completa florescência". Vários eram os argumentos que exaltavam o potencial de Porto Alegre para desenvolver esse esporte hípico. 0 jornal se firmava, principalmente, nas características históricas e culturais da então província, relacionando a região à Hungria, e, segundo o periódico, tendo, os habitantes, uma aptidão natural com trato com os cavalos, como podemos perceber:

E, entretanto, é justamente nesta província que os clubes de corrida deviam abundar e prosperar, porque o Rio Grande do Sul é a Hungria do Brasil, - é a província em que todos sabem andar a cavalo e em que o cavalo desempenha um importantíssimo papel na economia social. Nosso povo é extraordinariamente inclinado a esse gênero de diversão; é uma tradição que lhe vem do passado. ${ }^{36}$

O turfe, dessa forma, em Porto Alegre era visto como uma ação praticamente nata ao povo daquela região. Ao mesmo tempo em que a sua adoção significava a "importação" de hábitos tidos como evoluídos, civilizados, a vinculação a aspectos relativos a formação histórica e social do local eram percebidos como variáveis destacadas frente a outras partes do país, um diferencial. Esse esporte que ganharia distinção na capital do Rio Grande do Sul, para os articulistas, tinha condições de se desenvolver amalgamando práticas modernas com aspectos históricos. Um povo ligado fortemente ligado aos equinos em uma atividade europeia.

Ainda referenciando as corridas de cavalo como algo que estava inserido aos hábitos locais, a Gazeta de Porto Alegre ratificou que "há 50 anos, não conhecia, o rio-grandense, outras diversões públicas além das carreiras e das cavalhadas. Ainda hoje não há na campanha festa sem o divertimento das cavalhadas e não passa semana em que não hajam carreiras". ${ }^{37}$ Exaltando e justificando a inauguração de um hipódromo, o jornal listou alguns benefícios

\footnotetext{
${ }^{35}$ Gazeta de Porto Alegre, Porto Alegre, 15/05/1880, p. 1.

${ }^{36}$ Idem.

${ }^{37}$ Idem.
} 
que isso acarretaria, como o desenvolvimento da raça cavalar, que seria incentivado através das corridas. $O$ artigo dá como exemplo os casos de São Paulo e Pelotas, que, após a instalação de clubes de corridas, animais de boa raça foram introduzidos, contribuindo para o desenvolvimento dos equinos. Novamente o periódico apontou que "as carreiras são a diversão predileta de todo o verdadeiro filho da província", e "era de estranhar-se que a nossa cidade mais populosa não possuísse um clube de corridas com organização regular".

O folhetim buscou demarcar definitivamente as divergências entre as carreiras e o organizado turfe. O hipódromo seria o local de desenvolvimento de hábitos civilizados e modernos, e um aperfeiçoamento da primitiva, quase selvagem, carreira. Por um lado, o artigo valorizava as qualidades dos gaúchos, ${ }^{38}$ como a habilidade ao cavalgar e a intimidade com as lides do campo e com as corridas de cavalo. Colocava, no entanto, o turfe em um novo patamar. Seria o desenvolvimento e o aperfeiçoamento das rudimentares carreiras. Para o impresso, "o povo não deixará de tomar parte na festa, porque se trata de uma diversão favorita, porém em forma pouco usual" ${ }^{39}$ O termo utilizado, "pouco usual", nos parece que se refere à diferença em relação ao que seria praticado no hipódromo, onde um esporte muito mais refinado seria desenvolvido.

Nesse caso, como em diversos outros momentos apontados nesse estudo, é possível identificarmos o hibridismo esportivo ocorrido em Porto Alegre. O desenvolvimento do esporte fez com que nas décadas finais do século XIX houvesse uma terceira via em relação ao turfe. Não era o esporte britânico na sua essência, tão pouco uma carreira de cancha reta. No entanto, o que se praticava não deixava de ser o turfe, mas uma assimilação local das especificidades do esporte combinado a referenciais regionais. Em certa medida, uma modernização do que já se fazia no Rio Grande do Sul, como podemos perceber a seguir.

Para o jornal, "as carreiras entre nós são em geral por sistema muito primitivo, isto é, corredores em manga de camisa, com o lenço amarrado na cabeça e em cavalos não encilhados". Era necessária a modernização, a adequação da prática tão comum entre os sul-rio-grandenses ao modo europeu.

\footnotetext{
${ }^{38}$ É importante que deixemos claro que quando nos referimos ao termo gaúcho neste artigo, estamos fazendo menção ao gentílico do Rio Grande do Sul, independentemente da sua origem étnica. Não buscamos discutir acerca da etimologia da palavra, tão pouco temos a intenção de nos reportarmos ao gaúcho uruguaio ou argentino.
}

${ }^{39}$ Gazeta de Porto Alegre, Porto Alegre, 15/05/1880, op. cit. 
Seria uma questão de adaptação e evolução. Conciliar a habilidade do cavaleiro gaúcho, que foi comparado a um centauro, às técnicas e aos cavalos europeus puro sangue seria um fator fundamental para o sucesso do turfe em Porto Alegre:

Não desdenhamos do sistema, como não podemos desdenhar da maneira por
que montam os nossos centauros da campanha, embora seja mui diversa da
escola de montaria usada na Europa. O nosso cavaleiro é um herói, parece ligado
ao seu animal e não há perigo que o assuste, obstáculo que o detenha, desde que
esteja bem montado. A mesma coisa se dá com as carreiras pelo velho sistema
da província; há mister de mais audácia, de mais agilidade e força, para correr
como o fazem na cancha os nossos corredores do interior. ${ }^{40}$

Acontece que a campanha insistia que os antigos hábitos deveriam ser substituídos por práticas que colocassem Porto Alegre no patamar da civilização, dos grandes centros mundiais. Aquelas antigas carreiras representavam uma cidade que deveria ficar no passado e a adoção de maneiras refinadas, importadas do velho mundo, era essencial, como o próprio artigo declarou: “a civilização tem suas exigências; os usos do século passado não servem para o nosso século; uma populosa cidade, como a nossa, deve possuir um clube de corridas, em que o estrangeiro possa reconhecer o sistema usual em todos os países". ${ }^{41}$

Não era só a maneira de competir que deveria ser modificada para que o turfe gaúcho pudesse se assemelhar ao que era praticado na Europa. Os cavalos ingleses, que necessitavam ser introduzidos, não estavam habituados ao que se fazia nas carreiras, não se adaptavam a "práticas ultrapassadas", como correr sem sela. Até mesmo a estrutura física dos jóqueis estava sendo copiada, segundo o jornal: "fazem bem os fundadores do Hipódromo, adotando o sistema de corridas usual na Europa: Jóqueis de pouco peso, cavalos encilhados e observações de todos os preceitos de ordem". ${ }^{42}$ Também se incentivava a presença de um público cada vez mais heterogêneo. A partir de 1884, por exemplo, o Prado Boa Vista passou a não cobrar entrada das senhoras que fossem ao hipódromo. Uma provável tentativa de agregar novos frequentadores que não tinham, até aquele momento, o hábito de comparecer regularmente àqueles locais. ${ }^{43} \mathrm{~A}$ cidade crescia e se modernizava em diversos aspectos, ampliava ainda mais as opções ligadas ao mercado do entretenimento e inseria

\footnotetext{
${ }^{40}$ Idem.

${ }^{41}$ Idem.

${ }^{42}$ Ibidem.

${ }^{43}$ A Federação, Porto Alegre, 25/04/1884, p.2
} 
progressivamente um público heterodoxo com destaque para a inclusão das mulheres. É nesse contexto que se privilegiava ambientes coletivos como locais de diversão, onde os hipódromos também estavam conectados e confirmavam essa tendência.

Imagem 2: Anúncio de corridas no Prado Boa Vista com entrada gratuita para mulheres

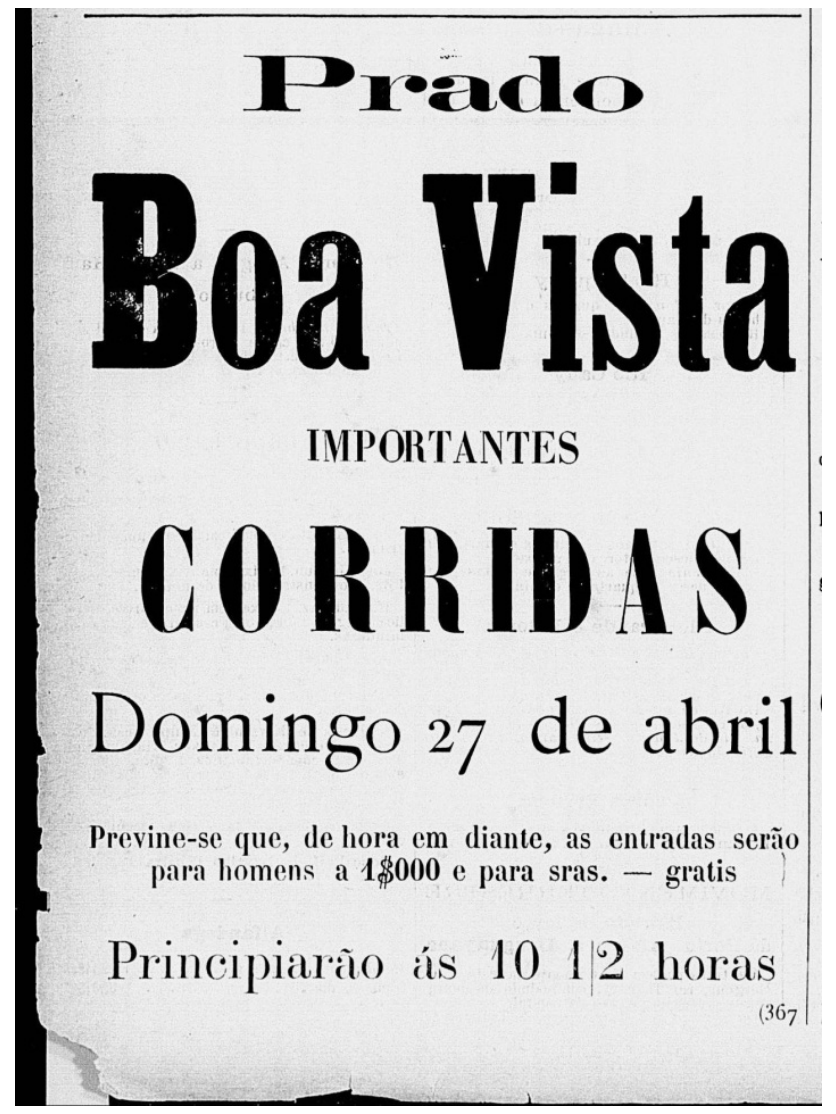

Fonte: A Federação, Porto Alegre, 25/04/1884, p. 2.

O uso de grande quantidade de regras, comum aos hipódromos do velho e do novo mundo, é uma característica da modernização das corridas de cavalo. No entanto, parece que, em Porto Alegre, a forte ligação com as práticas campeiras, associada a um regulamento uniforme e normas definidas, fazia com que houvesse uma espécie de transição ou intersecção entre 
o que era considerado primitivo e aquilo que buscava se inserir enquanto prática civilizada. Trata-se de um hibridismo na tentativa da "evolução" das corridas nos prados e uma estratégia para seduzir a população e, ao mesmo tempo, apresentá-la as novas condutas que deveriam ser praticadas. Atraíase a plateia, os "primitivos cavaleiros", para então "civilizá-los" no moderno Hipódromo Porto-Alegrense:

(...) os diretores do Hipódromo não quiseram privar o povo inteiramente do seu
antigo sistema e por isso lhes proporcionam uma corrida de cavalos sem selas,
permitindo que os próprios donos montem os seus animais e é ao vencedor
nesta corrida propriamente rio-grandense, que será oferecido o delicado mimo
(obra da província) exposto na vitrine da Livraria Americana. Assim, pois, foram
consultados todos os gostos, observadas todas as conveniências e só louvores
podemos ter para a inteligente direção que foi dada ao novo Hipódromo. ${ }^{4}$

O artigo clamava, ainda, para que esse hábito não se perdesse, destacando que a sua sobrevivência somente seria possível se houvesse a presença do público. Numa clara visão elitista, o jornal convocava para que se inscrevessem, como sócios, aquelas pessoas que têm interesse pelo assunto e "meios" para isso, sendo que "o povo, em geral, deve ao menos comparecer às corridas". ${ }^{45}$

O chamado do jornal se fez no sentido de não se deixar morrer o hipódromo, a exemplo do Club de Corridas, o que "seria uma vergonha para Porto Alegre, se não conseguíssemos conservar uma instituição que Pelotas, S. Paulo e a corte possuem, desenvolvendo-a cada vez mais". ${ }^{46}$ É como que se o desenvolvimento e a modernização da cidade estivessem atrelados à permanência da prática moderna, que era o turfe.

A Gazeta de Porto Alegre valorizava a identificação que a cidade apresentava com os cavalos, praticamente naturalizando as relações entre homem e o animal, quando definia que "trata-se no caso de um ramo de sport, que é inteiramente próprio da província, e que está aliás nas nossas tradições populares". ${ }^{47}$ Utilizava argumentos como a existência, em Porto Alegre, de bons cavalos e hábeis cavaleiros, ou ainda declarava que "o nosso povo entende do assunto". ${ }^{48}$ Tudo isso para enaltecer o esporte e reafirmar que a cidade possuía todas as condições necessárias para uma longa duração do hipódromo.

\footnotetext{
${ }^{44}$ Gazeta de Porto Alegre, Porto Alegre, 15/05/1880, p. 1.

${ }^{45}$ Idem.

${ }^{46}$ Idem.

${ }^{47}$ Idem.

${ }^{48}$ Idem.
} 
$\mathrm{O}$ artigo se encerrou com uma nova afirmação, onde destacou os valores modernos, assim como atentou que esses seriam brevemente aceitos. Era a necessidade de importação, tanto de hábitos quanto de animais europeus que honrariam o objetivo do hipódromo: "Estamos certos que logo que o gosto das corridas pelo sistema europeu houver feito mais seguidores, serão importados cavalos de raça, conseguindo-se assim o fim utilitário da nova instituição". A Gazeta de Porto Alegre ainda fazia o chamado: "Assim, pois, seja no dia 23 a devisa geral: ao Hipódromo! Ao Longchamps porto-alegrense!”. ${ }^{49}$ A instalação dos hipódromos se apresentava, praticamente, como um requisito necessário ao desenvolvimento de Porto Alegre, assim como a sua modernização.

Mesmo depois de 10 anos, percebemos que as relações entre os hábitos culturais dos gaúchos com relação ao cavalo e o esporte persistiram, como uma espécie de hibridismo entre a tradição e a modernidade, onde se aliava aquilo que estava enraizado nos comportamentos regionais com novos hábitos importados.

Gaúchos, com seus cavalos crioulos, vestidos conforme a tradição local, disputavam páreos nos hipódromos à moda europeia. Percebemos isso no jornal A Reforma, de 4 de agosto de 1900, que anunciou uma prova que seria realizada no Prado Rio-Grandense, permitindo somente a participação de cavalos crioulos, seguindo o método rio-grandense: "vestirão bombachas, não descalços, em mangas de camisa, um lenço atado na testa e um chicote, em cada mão. Os animais não levarão peça alguma de arreiamento, a não ser o indispensável, o freio". ${ }^{50} \mathrm{O}$ artigo ainda informava: "que o Derby vai ser pequeno para os curiosos nem é preciso adiantar" ${ }^{51}$. E parece que a expectativa se confirmou, pois em A Reforma, de 6 de agosto de 1900, a matéria sobre a corrida deixou bem claro: "como não sucedia a muito tempo, ficou ontem o Derby Club transbordando de espectadores". ${ }^{52}$ De acordo com o texto, esta corrida à gaúcha "era ansiosamente esperada pelo público que manifestava simpatia por todos os corredores e pouca firmeza em determinar qual seria o vencedor". ${ }^{53}$

Concomitantemente aos defensores das tradições, muitos eram os que lutavam pela modernização das corridas de cavalo. Inúmeros eram os argumentos para a criação dos hipódromos e para o desenvolvimento do

\footnotetext{
${ }^{49}$ Idem.

${ }^{50}$ A Reforma, Porto Alegre, 04/08/1900, p. 2.

${ }^{51}$ Idem.

${ }^{52}$ A Reforma, Porto Alegre, 06/08/1900, p. 2.

${ }^{53}$ Idem.
} 
turfe em Porto Alegre. Como já demonstramos, a prática desse esporte seria uma ação civilizadora e modernizadora, modificando hábitos considerados obsoletos.

Para além destes argumentos, o jornal Gazeta da Tarde publicou, em 29 de abril de 1895, um artigo assinado pelo seu diretor Germano Hasslocher. Dessa vez, a justificativa para a criação de um Jockey-Club era a necessidade de reprodução dos cavalos que, segundo a divulgação, foram praticamente dizimados pela revolução, "a ponto de não possuirmos mais cavalhadas, nem para as mais insignificantes exigências do serviço público". ${ }^{54}$ A referida ebulição é a Federalista (ou Revolução da Degola), que até hoje é considerada o mais sangrento conflito acontecido no sul do Brasil. Esse perdurou entre fevereiro de 1893 e agosto de 1895, entre Chimangos, também conhecidos como pica-paus, defensores do governo de Júlio de Castilhos, e os Maragatos, federalistas, opositores de Julio de Castilhos e do governo federal.

Publicado antes mesmo do fim do embate, o texto escrito por Germano percebeu a necessidade de um Jockey-Club e defendia veemente a sua criação. Segundo ele, necessário "hoje mais do que nunca". Ele ainda destacava a dependência brasileira em relação às criações equinas dos demais países do Prata, "que nos fazem pagar a peso de ouro os animais de que precisamos para o exército". ${ }^{55} \mathrm{Na}$ avaliação de Hasslocher, a revolução estava praticamente extinta, restando apenas alguns grupos de "homens sem fé nem crenças, sedentos de vingança", ${ }^{56}$ cujo único objetivo era perturbar a tranquilidade pública. Segundo o artigo, com a proximidade do fim do conflito, brevemente recomeçaria a vida regular nas estâncias.

Para o jornalista, essa seria a oportunidade de dinamizar ainda mais a criação de cavalos no estado, aperfeiçoando os métodos de reprodução. Germano destacou que "era muito primitivo o nosso sistema, tanto para a criação de gado cavalar como vacum". ${ }^{57}$ Complementando, ele defendia que o Estado intervisse na criação desses animais, animando os criadores através de premiações para exposições. Da mesma forma, haveria o incentivo, o que motivaria aqueles investidores de altas somas em cavalos puro-sangue importados, que se destinariam, também, à reprodução. O Jockey-Club, para além do esporte e da diversão, na interpretação de Germano Hasslocher, seria uma

\footnotetext{
${ }^{54}$ Gazeta da Tarde, Porto Alegre, 29/04/1895, p. 1.

${ }^{55}$ Idem.

${ }^{56}$ Idem.

${ }^{57}$ Idem.
} 
instituição "protetora do desenvolvimento da indústria criadeira de cavalos" ${ }^{58}$ O jornalista justificava a sua argumentação dizendo que, dessa forma, "será indubitavelmente o mais importante fator do nosso progresso na matéria". ${ }^{59}$ Mais uma vez o desenvolvimento do Rio Grande do Sul, ampliando a discussão para além dos limites esportivos, tinha como critério a adoção de modelos oriundos do velho continente, da mesma forma como as matrizes raciais dos cavalos que seriam reproduzidos no sul do Brasil.

O surgimento dessa entidade incentivaria, ao mesmo tempo, a moralização das disputas, sua disciplinarização e, não menos importante aos olhos do crítico, o desenvolvimento genético dos cavalos, significativo não somente para o esporte, mas a todo o serviço do povo gaúcho. Esse "trabalho" teria, como necessidade fundamental, o auxilio financeiro estatal. Germano finalizou o seu artigo neste sentido: "com o Jockey-Club que fundarmos as carreiras serão serias, dirigidas sempre por pessoal acima de toda suspeita, pois não visando interesse para a associação, só cuidará de firmar os seus créditos e tornar uma realidade os seus elevados intuitos." 60

Esse projeto, que teria como um dos objetivos o desenvolvimento esportivo com a adoção de uma série de medidas modernizadoras características de um Joquei-Clube, aos poucos foi tomando forma. No ano de 1899, o Correio do Povo publicou na sua coluna Sport, uma notícia sobre a formação dessa entidade em Porto Alegre ${ }^{61}$. O periódico depõe, em 22 de janeiro de 1899, que os diretores dos prados Independência e Rio-Grandense acordaram na forma de se criar um Joquei-Clube, seguido pelo mesmo regulamento do Joquei-Clube do Rio de Janeiro. Esse deveria ser instalado nas dependências de um dos prados, caso seja impossível nos Campos da Redenção. E, novamente a exemplo da capital nacional, os quatro hipódromos seguiram o formato dos do Rio, e tornaram-se sociedades esportivas sem fim lucrativo.

Não é de se estranhar que também houvesse discursos contrários ao turfe, ou, pelo menos a algumas práticas que neles aconteciam. Paralelamente à defesa do esporte, debates também eram travados em relação às apostas feitas nos cavalos. Podemos compreender que, de certa forma contraditória, era a defesa de uma prática, ao mesmo tempo, civilizadora e moderna, e, por outro lado, um hábito considerado imoral, a jogatina. É evidente que, juntamente

\footnotetext{
${ }^{58}$ Idem.

${ }^{59}$ Idem.

${ }^{60}$ Gazeta da Tarde, Porto Alegre, 29/04/1895, p.1.

${ }^{61}$ Correio do Povo, Porto Alegre, 22/01/1899, p. 1.
} 
com as denúncias de práticas desagradáveis que eram as apostas, justificativas ajudavam a legitimá-las, como o texto publicado no jornal Correio do Povo:

É certo que a aposta é um mal; mas no turfe é um mal necessário, mal comum, aliás, e inerente, sob esta ou aquela forma, a toda a espécie humana. O turfe em Porto Alegre pode presentemente ser considerado um salvador da mocidade inesperta. Cremos que só a nossa polícia ignora que em Porto Alegre funciona diariamente, além de inúmeras casas de jogo de cartas, seis de roleta e lansquenet bancado. Se a mocidade não tivesse os hipódromos para ir divertir-se aos domingos, invariavelmente seria, em sua maioria, arrastada a esses focos de perdição. ${ }^{62}$

Argumentos defendendo a prática das apostas ainda são entoadas pelos atuais sportman. Para o Jockey Clube Brasileiro, apostas em cavalos não são jogos de azar. Do total apostado, apenas uma parte é retirada para novos investimentos no desenvolvimento do turfe, sendo que o restante é devolvido aos ganhadores das apostas, de acordo com o Turfe no estado do Rio de Janeiro.63 As apostas incentivariam o desenvolvimento dessa "nobre" e "civilizada" prática.

Dos males o menor: se as apostas nos prados não eram agradáveis aos olhos de todos, também era uma atividade que servia de subsídio e incentivo a um esporte moderno, civilizado e superior, que era o turfe. Apostariam, portanto, em algo que lhes traria vantagem. Nesse caso, os jogos eram atos refinados e modernizantes, que atrairiam a mocidade para saudáveis costumes.

\section{Uma modernidade "cruzada": quando os crioulos superam os puro- sangue}

O discurso de modernização que acompanha as práticas esportivas engloba vários fatores daquilo que compreendemos enquanto campo. No século XIX (assim como em toda história do esporte), não bastava somente a execução da modalidade esportiva de acordo com um conjunto de normas. Os ideais de adequação atingiam muitas dimensões, que abrangiam aspectos de comportamento, estrutura física relativa à prática esportiva, técnicas, etc. No caso do turfe, um debate que cercava constantemente esta atividade, e que foi recorrente na imprensa da época, era a importância do desenvolvimento racial dos cavalos para a expansão e qualificação do esporte.

Em Porto Alegre, tivemos relatos de disputas entre os cavalos puro-sangue, considerados "o desenvolvimento máximo da raça", e mestiços sul-rio-grandenses, julgados por muitos como uma segunda linha equina,

\footnotetext{
${ }^{62}$ Correio do Povo, Porto Alegre, 21/07/1898, p. 3.

${ }^{63}$ JOCKEY CLUB BRASILEIRO. O turfe no estado do Rio de Janeiro. Rio de Janeiro, 1999.
} 
provenientes de vários cruzamentos de animais de diversas raças trazidas pelos colonizadores europeus a partir do século XVI, desenvolvendo-se selvagens, soltos nos campos sulinos. No caso, inúmeras vezes o resultado final das corridas refutava o discurso sobre a superioridade dos puros importados. Todavia, isso não era visto pela imprensa como algo negativo, mas, sim, como uma possibilidade de diferencial das criações gaúchas em relação às demais. Mais uma vez, as características específicas do sul do país em relação aos cavalos se destacariam frente ao restante do Brasil.

O jornal Gazeta da Tarde, de 16 de setembro de 1895, demonstrou um desses exemplos. 0 artigo tratou sobre a disputa do Grande Prêmio 20 de setembro, realizado no Prado Boa Vista, pelos "melhores puro-sangue que existiam em nosso turfe e pelo valente mestiço Frade" ${ }^{64}$ Estavam escritos para esse páreo, Aguazil, Pillo, Bismarck, Audinot, Honora, Centauro, Buenadicha, e Frade. Acontece que, após a disputa, chegou em primeiro lugar o único entre eles que não possuía uma raça definida. Com efeito, esse fato parece não ter sido estranhado pela imprensa, que exaltou o feito e valorizou o cavalo gaúcho:

A vitória do meio sangue rio-grandense sobre os puro sangue platinos causou alegria, mas não surpresa - pois já é a terceira vez que ele bate os puro sangue estrangeiros. Diz-se que eles estavam em mau estado, mas é inexato. Frade venceu brilhantemente em uma corrida admirável e com o tempo que deu teria vencido quase todos os Grandes Prêmios que se tem realizado no Rio de Janeiro - batendo os cavalos ingleses e franceses que mais tem figurado ali. Esta importante vitória que veio honrar a criação rio-grandense se presta a considerações importantes que faremos em subsequentes artigos. ${ }^{65}$

De fato, no dia seguinte, 17 de setembro de 1895, a Gazeta da Tarde discutiu novamente a vitória do meio sangue Frade sobre os puro-sangue concorrentes. Na matéria, se vê claramente a tentativa de legitimar a vantagem da mestiçagem gaúcha sobre os demais cavalos considerados superiores racialmente. A comprovação se dava através de uma série de comparações estatísticas de tempos obtidos pelos destacados equinos que competiam na capital fluminense, com o tempo feito por Frade no Grande Prêmio 20 de setembro. De acordo com os dados comparados, pelo seu desempenho, Frade seria o vencedor em todas as poules. Para o jornal, "desta simples confrontação vê-se que o meio sangue rio-grandense bateria facilmente todos os vencedores dos Grandes Prêmios Nacionais batendo os puro sangue do Rio e São Paulo". ${ }^{66}$

\footnotetext{
${ }^{64}$ Gazeta da Tarde, Porto Alegre, 16/9/1895, p. 3.

${ }^{65}$ Idem.

${ }^{66}$ Gazeta da Tarde, Porto Alegre, 17/9/1895, p. 3.
} 
As comparações que exaltavam os cavalos rio-grandenses não se restringiam a Frade. Eram muitas as apologias aos mestiços criados no Rio Grande do Sul, como "Tenerife", que "bateu em São Paulo a trote todos os cavalos da sua idade, mesmo de puro sangue"; "Diactor, outro meio sangue rio-grandense, percorreu em 1892 em São Paulo os 1450 metros em 93 segundos - tempo que nenhum puro sangue estrangeiro fez naquele ano naquele turfe". ${ }^{67}$

Se existia o elogio e a tentativa de comprovação da superioridade dos cavalos gaúchos frente aos importados, também havia uma orientação econômica nesse interesse. Para os criadores do Rio Grande do Sul, bastaria aliar as raças estrangeiras à nativa do sul do Brasil para que os melhores exemplares fossem garantidos e, consequentemente, o mercado nacional fosse monopolizado. Esse discurso pode ser percebido no jornal Gazeta da Tarde, que destacou:

Chegaremos a animadora conclusão de que nossos simples meio sangue são suficientes para bater os puro sangue paulistas e fluminenses e que só de nós depende monopolizarmos aqueles importantes mercados de produtos nacionais. Para isso - foi o que quisemos mostrar - não nos é absolutamente necessário empatar grandes capitais finíssimos e éguas puro sangue; qualquer criador de poucos recursos com garanhões estragados e baratos como Emilio $2^{\circ}$, St. Leon e o pai de Frade e as nossas éguas crioulas poderá obter produtos extraordinários como os que acabamos de lembrar. ${ }^{68}$

Aliado a essas justificativas, explicações de cunho geográfico ajudavam a legitimar a superioridade racial dos equinos mestiços do sul do Brasil frente aos estrangeiros, onde "condições cósmicas entram por muito nestes resultados". ${ }^{69}$ No entanto, a principal justificativa para essa superioridade no desempenho era realmente a raça crioula ${ }^{70}$, nativa do sul do Brasil, que, com suas qualidades, influenciaria beneficamente os cavalos mestiços aqui produzidos. A exaltação era tanta ao equino sul rio-grandense que o periódico declarou que "é o sangue crioulo, oriundo da nossa raça crioula, incontestavelmente a melhor raça cavalar que existe no mundo, e a mais suscetível de melhoramentos". ${ }^{71}$

Segue, na edição seguinte, a defesa das qualidades do cavalo rio-grandense. Na Gazeta da Tarde, de 18 de setembro de 1895, novamente um

\footnotetext{
${ }^{67}$ Idem.

${ }^{68} \mathrm{Idem}$.

${ }^{69}$ Idem.

${ }^{70}$ Para saber mais sobre a origem e as características da raça crioula, consultar o site da Associação Brasileira de Criadores de Cavalos Crioulos (ABCCC): http://www.cavalocrioulo.org.br/studbook/cavalo_crioulo

${ }^{71}$ Gazeta da Tarde, Porto Alegre, 17/9/1895, p. 3, grifos nossos.
} 
comparativo foi desenvolvido entre o meio sangue Frade, dessa vez, com os puros-sangue estrangeiros vencedores dos Grandes Prêmios Fluminenses. Mais uma vez, foi feita uma tabulação dos cavalos com seus respectivos escores para legitimar a informação de que o animal gaúcho sairia vencedor em todas as corridas com seus adversários imigrantes. ${ }^{72}$

Parece-nos que o posicionamento do periódico frente à qualidade dos cavalos importados, em nenhum momento, minimizou o equino nacional. Ao contrário, aparentemente, a Gazeta estava adversa a uma tendência de importar matrizes biológicas, valorizando o animal nativo e destacando a sua potencialidade:

Imaginem, pois, os criadores rio-grandenses o que teria feito este meio sangue no Rio, e o que poderia fazer ainda, se estivesse inscrito no Stud Book brasileiro - e tratando de inscrever seus produtos - continuem a criar confiadamente por que não tardará muito que outro meio sangue - excepcional como o Frade - vá ao turfe fluminense honrar a criação rio-grandense - encaminhando para os nossos paupérrimos estabelecimentos de criação as quantias fabulosas que vão anualmente para estrangeiros em troca de animais que, pela maior parte, podem ser batidos pelos nossos meio sangues. ${ }^{73}$

Supostamente, o jornalista responsável pelas crônicas relativas ao turfe era um criador de cavalos, o que, em parte, pode justificar a valorização exacerbada dos animais locais. Na Gazeta da Tarde, de 19 de setembro de 1895, o cronista anunciou a sua retirada temporária à sua fazenda de criação. Ele agradeceu a gentileza pelo acolhimento do que chamou de "insignificantes escritos sobre o turfe", que julgou "no desejo sincero de concorrer para que ele se torne moralizado e útil como deve e como infalivelmente, há de ser". ${ }^{74}$

$\mathrm{O}$ articulista militava a favor de uma série de mudanças necessárias aos nossos hipódromos, uma maior organização e o cumprimento dos objetivos dos prados, que se relacionavam ao desenvolvimento da raça cavalar, sendo as instituições responsáveis pelo estímulo às criações equinas: "com programas bem organizados, poderão obter maiores lucros favorecendo ao mesmo tempo, como é seu dever, os criadores, despertando neles o estímulo e o interesse e a confiança no público". ${ }^{75}$ Inserido nesse contexto, o apelo se dava no sentido de que os prados "sejam úteis e não continuem a ser, como tem sido meras casas de jogo cujo barato vai humanamente aproveitar

\footnotetext{
${ }^{72}$ Gazeta da Tarde, Porto Alegre, 18/9/1895, p. 3.

${ }^{73}$ Idem.

${ }^{74}$ Gazeta da Tarde, Porto Alegre, 19/9/1895, p. 2.

${ }^{75}$ Idem.
} 
em parte à pobreza". ${ }^{76}$ Esse apelo se conjuga aos aspectos defendidos pelos esportes modernos, como a transparência nas disputas, regras claras, além da sua característica civilizacional, útil para o desenvolvimento humano. Era isso que o turfe em Porto Alegre deveria ser.

A apologia à criação de cavalos no Rio Grande do Sul, assim como o desenvolvimento do turfe e dos hipódromos, ganhava, nas palavras de seu defensor, premissas que iam bem além de interesses esportivos. Da sua justificativa, faziam parte argumentos econômicos, bélicos e de soberania, que ajudavam na sustentação das suas ideias:

Quando o governo estudar este magno assunto compreenderá que o turfe e especialmente os hipódromos são as fontes mais seguras e econômicas para melhorar a raça cavalar e que lhe compete patrioticamente o turfe e os hipódromos para que amanhã possa ele ter bons e numerosos cavalos não só para vencer uma revolução, como ainda para opor-se a uma guerra externa, o que é muito mais grave. ${ }^{77}$

A questão do desenvolvimento racial dos cavalos rio-grandenses foi apenas uma das variáveis em um grande discurso permeado de ideias de modernidade. No caso de Porto Alegre, em que existia uma relação diferenciada e muito próxima aos animais, se criou uma nova adaptação do pensamento moderno às características locais. Inserido nessas relações, questões econômicas, históricas e até mesmo geográficas fizeram com que a capital do Rio Grande do Sul percebesse essas ideias de maneira diferenciada num contexto singular no Brasil. ${ }^{78}$

\section{Para concluir}

O cavalo é elemento expressivo em boa parte da história do Rio Grande do Sul, livre de possíveis debates regionalistas. Consequentemente, não foi diferente na sua mais importante cidade nas décadas finais do século XIX. Independentemente da origem étnica do morador da capital do Rio Grande do Sul, a proximidade do povo que ali habitava com gado bovino ou equino foi uma característica histórica que pode ser percebida de forma contundente no cotidiano da cidade em diversas medidas.

\footnotetext{
${ }^{76}$ Idem.

${ }^{77} \mathrm{Idem}$.

${ }^{78}$ Sobre as especificidades porto-alegrenses e uma análise comparativa do surgimento e desenvolvimento do campo esportivo no Rio de Janeiro e Porto Alegre ver: KARLS, Cleber Eduardo. Modernidades sortidas: 0 esporte oitocentista em Porto Alegre e no Rio de Janeiro, op. cit.
} 
Porto Alegre, mesmo crescendo, recebendo imigrantes estrangeiros, sendo o polo regional mais importante do estado, também era a área de interseção entre o Rio Grande do Sul pecuarista, latifundiário e escravista, com a região que tinha, como característica, a agricultura imigrante europeia de pequena propriedade rural e mão de obra familiar, assim como a urbanidade de uma cidade cada vez mais destacada no cenário regional e nacional.

No caso do esporte em Porto Alegre e, mais especificamente em relação ao turfe, essa ligação se torna ainda mais visível. Todavia, o que aconteceu em Porto Alegre no século XIX não foi o resultado somente desta variável. No sul brasileiro, uma série de peculiaridades fez com que esta prática oriunda do Velho Mundo ganhasse novas cores e uma inédita leitura na Porto Alegre oitocentista.

Sintonizada às ideias da época, a capital do Rio Grande do Sul, aliou a sua história a pensamentos de modernidade que estavam influenciando praticamente todo o mundo ocidental. Porto Alegre desejava se tornar cosmopolita, se modernizar e desenvolver. No entanto, estas não eram ideias estanques que estavam alheias às características locais. É por isso que podemos afirmar que o esporte, e, em especial, o turfe, adquiriram no limite austral brasileiro características próprias, resultado desse conjunto miscigenado de fatores que deu origem ao esporte praticado na capital do Rio Grande do Sul.

Não estamos afirmando que o que aconteceu em Porto Alegre em relação ao desenvolvimento do turfe não ocorreu em diversos outros locais do globo. Como destacamos, esse é um esporte de origem britânica que se espalhou por grande parte do planeta, tendo como referência o que era praticado no velho continente. Todavia, ao estudarmos esse processo de formação e desenvolvimento na capital do Rio Grande do Sul, identificamos uma assimilação particular das características do esporte, associadas fortemente às peculiaridades da formação cultural, étnica e geográfica do sul do Brasil.

Com efeito, o que se praticava (ou ainda se pratica) em Porto Alegre, está relacionado a um processo de modernização que esteve presente em todo o Brasil em diversas variáveis, associando-se a uma vinculação regional já existente com as diversões, especialmente ligadas ao cavalo e a vida no campo. Enfim, Porto Alegre e seu processo de desenvolvimento esportivo é um caso com individualidades próprias, que não aconteceu somente com o turfe, mas que tem nele um exemplo destacado.

Artigo recebido para publicação em 04/04/2019 Artigo aprovado para publicação em 21/02/2020 